\title{
ETUDIANTS, CHERCHEURS, ÉCRIVAINS À LA CROISÉE DES LANGUES ET DES CULTURES
}

\author{
Karine Rouquet-Brutin
}

RÉSUMÉ: Cette communication souhaite ouvrir quelques pistes de réflexions sur les enjeux subjectifs, épistémologiques, politiques impliqués par le franchissement des frontières. Je m'intéresserai aux démarches des étudiants venus poursuivre leur recherche en France confrontés à une autre culture, une autre langue, un autre régime de discours et à celles d'écrivains, penseurs, chercheurs, venus d'ailleurs qui ont choisi de rester en France et d'écrire en français : Julia Kristeva (universitaire, psychanalyste, écrivain d'origine bulgare), François Cheng (chercheur, traducteur, poète d'origine chinoise), Janine Altounian (traductrice de Freud, essayiste, d'origine arménienne). C'est à l'occasion du déplacement et du franchissement des frontières qu'émerge la question qui a besoin de la langue et de la culture de l'autre pour se formuler.

MOTS-CLÉS: l'interculturalité. Langue. Puissance.

RESUMO: Esta comunicação deseja abrir alguns caminhos de reflexão sobre as questões subjetivas, epistemológicas e políticas implicadas no atravessamento de fronteiras. Serão abordados os percursos de estudantes que vão à França para realizar pesquisas acadêmicas e seus procedimentos no confronto com outra cultura, outra língua, outro regime de discurso. Serão, ainda, objeto desta comunicação escritores, pensadores e pesquisadores, que, vindos de outros lugares, escolheram ficar na França e escrever em francês: Julia Kristeva (acadêmica, psicanalista, escritora de origem búlgara), François Cheng (poeta, tradutor, acadêmico de origem chinesa), Janine Altounian (tradutora de Freud, ensaísta, armênia nascida na França). É no deslocamento, no atravessamento de fronteiras, que emerge a questão da necessidade da língua e da cultura do outro para formular-se.

PALAVRAS-CHAVE: Interculturalidade. Língua. Poder.

\section{INTRODUCTION}

«Passer par le dehors d'une autre pensée, d'une autre culture, quelque qu'elle soit, c'est être convié à revenir, à réinterroger ce qu'on n'interrogeait pas » ${ }^{1}$ a déclaré François Jullien, philosophe et spécialiste de la Chine, dans la conférence d'ouverture d'un colloque que nous avons organisé à la Cité internationale universitaire de Paris en 2003. Ce colloque avait pour titre : «Etudier, chercher ailleurs : les étudiants étrangers

\footnotetext{
${ }^{1}$ François Jullien: «Conférence d'ouverture », in Etudier,chercher ailleurs : les étudiants étrangers dans l'université française, Paris, Cité-débats, Octobre 2004, p. 29-49.
} 
dans l'université française $»^{2}$. François Jullien nous a expliqué, et je reviendrai dans le cours de cet exposé sur sa démarche, comment son détour par la Chine, une civilisation qui s'est développée totalement en dehors du monde occidental et sans référence à lui, lui avait permis en retour de «pouvoir en quelque sorte remettre en perspective la pensée européenne », « penser l'impensé de la philosophie occidentale ».

C'est sous l'angle des enjeux épistémologiques mais aussi subjectifs et politiques impliqués par les déplacements des étudiants que je souhaite ouvrir cette réflexion sur les constructions identitaires à la croisée des langues et des cultures. Il y a environ deux millions cinq cent mille étudiants voyageant à travers le monde en quête d'études. En 2009, 267000 d'entre eux sont venus étudier en France. Plus d'un tiers des étudiants inscrits en doctorat en France sont de nationalité étrangère ${ }^{3}$. Cette situation infléchit les politiques d'accueil des états. Si les Etats-Unis ou le Canada cherchent à attirer les étudiants pour la totalité de leur formation, la France, elle, privilégie leur accueil au niveau du deuxième et troisième cycle dans le cadre d'accords avec les universités partenaires ${ }^{4}$.

Ceci n'est pas sans conséquences : une grande partie des étudiants arrivent en France sans avoir bénéficié d'une formation initiale dans l'université française : ils entrent dans un environnement social et scolaire dépaysant et doivent se familiariser dans un temps souvent très court avec l'institution universitaire, avec un certain régime de discours et avec des savoir-faire considérés comme acquis en termes de normes, de codes intellectuels et méthodologiques. Je me limite ici volontairement à l'aspect universitaire, car les problèmes rencontrés par les étudiants sont beaucoup plus vastes.

Etudier, penser, écrire dans une autre langue engage celui qui s'y risque dans une aventure singulière qui peut être douloureuse, conduire à une situation d'impasse ou devenir le ferment d'une nouvelle liberté.

Le travail avec ces étudiants m'a rendue sensible aux dynamiques subjectives qui s'inscrivent dans le passage des frontières, le déplacement des objets de recherche d'une langue à l'autre, le rapport à sa propre langue et à son histoire qui est rendu plus aigu par l'expérience de la vie et l'implication dans le travail universitaire sur un sol

2.Selon I'UNESCO et Ronan Vourc'h, «Les doctorants: profils et conditions d'études », Rapport de l'Observatoire de la Vie Etudiante n²4, juin 2010.

${ }^{4}$ Selon M. Jean-Yves de Longeau, sous-directeur de l'égalité des chances et de la vie étudiante à la Direction Générale pour l'Enseignement Supérieur et l'Insertion Professionnelle/ DGESIP lors d'un débat à la Ciup « L'Odyssée d'une utopie », mai 2010. 
étranger. Autrement dit à ce que permet le déplacement, la traversée des frontières et le choix de la langue française comme langue de recherche, comme langue de travail scientifique.

Précisons tout de suite le lieu, la place, l'expérience qui me permettent de formuler cette hypothèse et celles qui vont suivre. J'accueille, en tant qu'enseignante détachée de l'Université Paris 7, - ma discipline est la littérature- aux côtés de mes collègues psychanalystes, des étudiants étrangers dans l'antenne du Bureau d'Aide Psychologique Universitaire-Pascal ${ }^{5}$. Le Bureau d'Aide Psychologique Universitaire est un centre de consultation pour les étudiants qui ressentent le besoin d'une aide psychologique. Il est un des établissements de la Fondation Santé des Etudiants de France $^{6}$. L' antenne du BAPU s'est ouverte en 2000 au sein d'une structure, le Relais social international, elle-même inscrite dans un lieu de vie et d'hébergement, la Cité internationale universitaire de Paris qui rassemble plus de cinq mille cinq cent étudiants venus de tous les pays du monde. Cette cité internationale est le lieu historique de la réalisation d'une utopie née après la première guerre mondiale : favoriser la concorde entre les peuples par les échanges d'étudiants ${ }^{7}$.

De cette place particulière, enseignante travaillant en liens étroits avec des psychanalystes, dans une structure indépendante de l'université mais liée à elle, structure inscrite dans un lieu hautement symbolique qui fait résonner toutes les implications politiques du devoir d'hospitalité, je n'ai pu manquer d'apercevoir tout le fracas du monde résonner dans les sujets de recherche, ceci dans toutes les disciplines.

Je donnerai un aperçu de ces sujets dans ma première partie qui interroge les enjeux subjectifs, épistémologiques et politiques qui sous-tendent, à mon sens, le travail des étudiants.

\footnotetext{
${ }^{5}$ Les étudiants sont accueillis par des psychanalystes.

${ }^{6}$ La Fondation Santé des Etudiants de France assure le suivi médical et les études de jeunes gens empêchés d'étudier en raison de leur maladie. Elle dispose de 13 cliniques, certaines sont consacrées à des jeunes gens souffrant de troubles somatiques, d'autres accueillent des jeunes gens souffrant de troubles psychiques. La devise de la Fondation est « Etudier quand même ».

${ }^{7}$ La création de la Cité internationale universitaire de Pariseut lieu dans le contexte du mouvement pacifiste de l'Entre-deux-guerres. Ses fondateurs, acteurs publics ou mécènes, porteurs d'un idéal humaniste, souhaitaient créer une " école des relations humaines pour la paix. "Sa vocation est de contribuer à l'entente entre les peuples en favorisant les amitiés entre les étudiants, les chercheurs et les artistes du monde entier.
} 
Dans une seconde partie, j'aborderai l'expérience d'écrivains, de penseurs venus d'ailleurs qui ont choisi, pour des raisons diverses et parfois sous la contrainte ou dans l'impossibilité de faire autrement, de rester en France, de devenir citoyens de ce pays et de produire leur pensée dans la langue de cette terre d'adoption. J'ai choisi Julia Kristeva, François Cheng, Janine Altounian. Julia Kristeva et François Cheng sont écrivains et chercheurs : ils viennent de pays marqués par l'emprise totalitaire - la Bulgarie, la Chine - sans toutefois le revendiquer comme tel. Janine Altounian est d'origine arménienne ; essayiste et traductrice de Freud, fille de survivants du génocide, elle travaille sur la mise à jour de son patrimoine traumatique menacé de disparition. Tous sont artisans d'une création et d'une réflexion qui se construit entre deux cultures et deux langues. En ce sens, l'appel à ces auteurs m'a paru susceptible d'éclairer la dynamique du métissage, dynamique sensible mais souvent inconsciente dans la démarche de ceux qui partent étudier, chercher ailleurs, en quête d'un tiers autre, pour donner lieu, légitimation, droit de cité à une réflexion qui pourrait peut-être ne pas avoir lieu dans le pays d'origine ou ne pas avoir de lieu. Et c'est à l'occasion du déplacement et du franchissement des frontières qu'émerge la question qui a besoin de la langue et de la culture de l'autre pour se formuler.

\section{ETUDIER, CHERCHER AILLEURS. PARCOURS D’ETUDIANTS}

Un grand nombre de sujets de Master et de Thèse impliquent le pays d'origine et ceci dans toutes les disciplines.

1. Des sujets de recherche qui impliquent le pays d'origine

La liste des sujets comparatifs est très importante qui permettent d'évaluer les coutumes, les pratiques, les législations en croisant les perspectives : en Droit: La protection du patrimoine au Vénézuela et en Europe ou encore La protection collective des consommateurs en France et en Argentine ; en Linguistique, La temporalité dans les langues chinoise et française ; en Sciences de l'éducation, l'introduction de l'ordinateur à l'école: une étude menée en France et au Mexique. En Théâtre, l'influence du 
Kathakali (théâtre dansé en Inde) sur des metteurs en scène contemporains, Ariane Mnouchkine et Peter Brook.

Ou encore les sujets n'impliquent pas une comparaison ou une mise en relation mais portent directement le pays d'origine. En Cinéma « Fabulation de l'altérité dans le cinéma brésilien : le cas de Cidade de Deus » ou encore la filmographie historique représentant en Corée du sud la guerre des deux Corées ; en Droit, La réparation des dommages environnementaux en droit positif béninois ; en Sociologie, les associations de chômeurs en Argentine, La place de la femme dans les programmes de lutte contre la pauvreté au Mexique, les populations déplacées en Colombie; en Architecture, Les traces de la dictature dans la ville de Buenos Aires; en Histoire, Les conflits environnementaux en Espagne pendant la dictature, La criminalité en Tunisie pendant la période coloniale; en Economie, Le travail salarié des femmes en Afrique subsaharienne, les populations déplacées en Angola; en Psychologie, Les représentations sociales de l'enfant handicapé mental au Mali. Nombreux sont les sujets qui portent sur la condition féminine au Yémen, au Liban, en Algérie, au Maroc, au Mexique, en Tunisie, aux Philippines et interrogent la place de la femme dans les sociétés musulmanes et conservatrices, la discrimination salariale entre hommes et femmes, ou encore l'entreprenariat féminin.

Certains sujets révèlent l'implication immédiatement politique du déplacement. On vient en France pour aborder et travailler une question interdite dans son propre pays. Ainsi une étudiante turque, vient faire son master en Etudes politiques sur L'implication des médias turcs dans les assassinats politiques des leaders d'opposition. Une étudiante libanaise est venue soutenir son mémoire en Psychologie sur les Kamikazes (candidats à la mort volontaire) du Hezbollah dans le contexte du conflit avec Isräl. Une étudiante chilienne en Sciences sociales, interroge les formes artistiques comme modalités d'élaboration de la dictature.

Si un grand nombre de sujets travaillés en France nomment dans leur titre le pays d'origine, un moins grand nombre de sujets, selon mon appréciation subjective, concerne le pays d'accueil. Par contre presque tous les étudiants disent avoir besoin de se référer à la pensée théorique française développée dans les équipes de recherche auxquelles ils veulent s'agréger. A la pensée française comme outil, non comme finalité de l'étude. Mais un étudiant qui vient produire et soutenir en France une thèse sur 
Saussure, la révolution française ou la législation européenne est conduit par le fait de travailler dans une autre langue des objets qui relèvent d'une autre culture, à utiliser le prisme de cette culture et de ses institutions comme outil de pensée, à « dépayser sa pensée » comme le dit François Jullien.

Le déplacement des étudiants en France tel que je peux l'appréhender articule deux mouvements : celui d'une affiliation consentie au pays d'accueil, à sa culture, à ses institutions universitaires, au développement de sa réflexion théorique et de ses méthodologies de recherche; à partir de cette affiliation et au travers de la discipline élue, un mouvement qui fait retour sur le pays d'origine, le natal pour l'interroger, le mettre en perspective, déployer une question qui le concerne à l'aide des savoirs constitués en France qui, ajoutés aux savoirs théoriques acquis là d'où l'on vient constituent un socle d'analyse.

Passer une frontière, étudier ailleurs est susceptible de donner une assise depuis laquelle un sujet peut se retourner vers le pays d'où il vient, regarder vers l'arrière tout en se projetant vers l'avenir.

Tel fut le parcours que retraça François Jullien, à l'ouverture du premier colloque «Etudier, chercher ailleurs: les étudiants étrangers dans l'université française ». Mais lui choisit d'aller étudier en Chine, à Pékin et à Shangaï. Les réflexions qui vont suivre illustrent magistralement la stratégie épistémologique du détour par un autre pays et une autre culture.

\section{DEPAYSER LA PENSEE ${ }^{8}$}

Aujourd'hui, professeur à l'Université Paris 7- Denis Diderot, directeur de l'Institut de la pensée contemporaine et auteur de nombreux livres qui tous instaurent un dialogue entre la pensée occidentale et la pensée chinoise, il est revenu sur le temps et les raisons qui l'ont amené à se retrouver étudiant dans une Chine qui sortait du communisme. Jeune normalien, il voulait réinterroger la pensée grecque. Pour un helléniste s'ouvrait la voie du sanscrit mais c'était rester dans nos racines indoeuropéennes, dans le monde de la grammaire, de la métaphysique ; or il cherchait un lieu extérieur par la langue et par l'esprit et une pensée aussi explicitée et commentée

\footnotetext{
${ }^{8}$ François Jullien : «Conférence d'ouverture », in Etudier,chercher ailleurs : les étudiants étrangers dans l'université française, op. cit.
} 
que la pensée grecque : c'est ainsi la Chine s'est imposée. La Chine constitue pour lui une « hétérotopie ${ }^{9}$, « un lieu autre » produisant « un dépaysement de l'esprit ».

«Comment avoir prise sur ce qu'on pense et plus encore sur l'impensé qui en constitue les bases, cet impensé en amont de la pensée, à partir duquel on pense et, par là-même auquel on ne pense pas ? ${ }^{10}$. Telle est la question philosophique qui anime la quête de François Jullien : il s'agissait pour lui de rompre avec l'histoire de la philosophie, de sortir «du bain de la pensée indo-européenne », de «sortir de tout ce qui la tend, la sous-tend, la justifie par cette sorte d'extrapolation, en faisant effraction par le dehors chinois ».

Ainsi, son détour par la Chine, lui a permis de «pouvoir en quelques sortes remettre en perspective la pensée européenne » : «penser l'impensé de la philosophie occidentale ». Ainsi encore, explique-t-il, découvrir que le verbe «être » n'existe pas en chinois classique lui permit de percevoir que la Chine s'était constituée en dehors de la pensée de l'essence, de l'ontologie et de ses grands philosophèmes : l'être, Dieu, la liberté. L'extériorité chinoise ouvre un point de perspective pour interroger la philosophie occidentale dans ce qu'elle ne pense pas et qui pourtant la fonde: «j'ai fait du chinois pour lire Platon $»^{11}$ affirme ce philosophe.

Pour en revenir aux démarches des étudiants, l'immersion dans une autre culture, la souffrance d'y être en perte de mots et de grammaire, l'immense travail d'identification des codes et des lois implicites régissant non seulement la vie quotidienne et la vie universitaire mais le discours à tenir, la confrontation à l'exigence d'écrire leur mémoire pour ce destinataire qu'est l'université française, dans une langue qui impose une autre vision du monde, crée un écart différenciateur, une instance tierce par où ne cessent de s'ouvrir des point de perspective sur le pays d'où l'on vient, sur le natal. Observateurs attentifs des mœurs universitaires et des traditions discursives de cet étrange pays où ils ont choisi d'étudier, les jeunes gens sont conduit par le travail d'affiliation à questionner en retour leur culture universitaire, leurs modes de pensée et d'énonciation. Je précise que je me limite ici au plan universitaire car ce sont souvent

\footnotetext{
${ }^{9}$ François Jullien précise que l'« Hétérotopie » est un concept opposé à « utopie »; il est forgé par Michel Foucault dans la préface de Les mots et les choses.

${ }^{10}$ François Jullien, in Nouvelles clés, $n^{\circ} 34$, été 2002.

${ }^{11}$ Toutes les citations données proviennent de la conférence d'ouverture de François Jullien, Étudier, chercher ailleurs : les étudiants étrangers dans l'université française, op.cit..
} 
tous leurs liens, toutes leurs attaches, leur identité même qui deviennent objet de questionnement.

Et c'est un autre effet du voyage et du franchissement des frontières : le détour par le dehors, par le lointain permet d'interroger le proche, le natal. « L'exil, traversée de l'étranger est reconnaissance du propre. Dans le lointain, on découvre le proche et aller vers le lointain est une approximation du natal » nous explique le psychanalyste Edmundo Gomez Mango dans un article remarquable «La langue et 1'exil » : «parce que seul et loin de la source, on s'en rapproche pour s'y réfugier, pour trouver asile dans son intimité proche» ${ }^{12}$.

\section{ECRIVAINS ET PENSEURS ENTRE DEUX LANGUES ET DEUX CULTURES}

Julia Kristeva, François Cheng et Janine Altounian ont retracé leurs parcours dans leurs écrits, et porté témoignage du déplacement de leurs inscriptions dans la langue et la culture du pays d'accueil. Cette culture est devenue le creuset où ils ont forgé depuis la patrie perdue mais toujours présente de nouvelles identités qui nous interpellent: «Je suis un monstre de carrefours » proclame Julia Kristeva, quand François Cheng se déclare «passeur » d'un dialogue entre l'Orient et l'Occident; « passeur » comme Janine Altounian, mais pour elle, il s'agit du passage frayé par elle à l'héritage de ses ascendants arméniens au sein de la culture du pays où se réfugièrent ses parents, la France.

Voici trois écritures du métissage qui conduisent de l'aveu de leurs auteurs à une expérience de l'être.

\section{Julia Kristeva, l'hybride, la migrante}

Julia Kristeva est d'origine bulgare : elle a été élevée dans un milieu francophile épris des lumières de la pensée française, en cette partie de l'Europe qui souffrit du totalitarisme soviétique. C'est tout naturellement qu'elle vient poursuivre ses études en France où elle se marie; elle est aujourd'hui une universitaire et psychanalyste française, écrivaine, essayiste, romancière qui ouvre de nombreux terrains de réflexion

\footnotetext{
${ }^{12}$ Edmundo Gomez Mango, «La langue et l'exil », Cahiers intersignes : Parcours d'exil, n`3, automne 1991, p.122 et 123.
} 
dont la réflexion sur l'étranger dans « Etrangers à nous-mêmes » ${ }^{13}$. Elle a reçu en 2004 le premier prix Holberg, créé sur décision du Parlement norvégien pour honorer une recherche exceptionnelle dans les sciences humaines. Elle se présente elle-même ainsi : écrivaine, essayiste, d'origine bulgare, française d'adoption, américaine de cœur et cosmopolite.

Nous nous appuierons principalement sur son livre Etrangers à nous-mêmes et sur l'article « Ecrire en français » ${ }^{14}$ pour retracer son parcours tel qu'elle-même nous le donne à connaître.

Remarquons d'abord que le passage d'une frontière lui ouvre un champ nouveau, la psychanalyse, et déplace ses recherches tournées d'abord vers la linguistique et la sémiologie, du côté des profondeurs de la psyché. Dès lors, celle dont Barthes écrivait «elle change la place des choses » se déplace entre les langues et les disciplines dont elle ne cesse de repousser les bornes, les limites, les frontières. C'est d'ailleurs cette position frontalière qui est donnée comme point de perspective: «c'est en se situant à l'interface des diverses 'disciplines' qu'on peut avoir une chance d'élucider tant soit peu ce qui reste toujours énigmatique : la psychose, la sublimation, la croyance et le nihilisme, la passion, la guerre des sexes, la folie maternelle, la haine meurtrière ${ }^{15}$.

C'est sur le terrain de la langue que s'éprouve le plus rageusement le conflit lié à l'abandon de la langue natale et la revendication ultime d'être «vouée à une parole étrange, étrangère, ni d'ici, ni de là » d'où émerge la revendication d'une identité «nomade ». Aussi la suivrons-nous dans le procès sans complaisance, mais non sans humour, qu'elle adresse à son pays d'adoption.

«Les français, des gens qui sont parce qu'ils pensent »

En spécialiste de la langue, elle détaille les vertus particulières de la langue. Elle souligne «la clarté logique, l'impeccable précision du vocabulaire, la netteté de la grammaire de la langue française qui séduisent son « esprit de rigueur », mais pointe les possibles dérives du raisonnement quand l'argumentation, dit-elle, «s'évide en séduction, en ironie ». L'observation de nos traits de caractère nationaux se fait plus

\footnotetext{
${ }^{13}$ Julia Kristeva, Étrangers à nous-mêmes, Folio essais, 1988.

${ }^{14}$ Julia Kristeva, , in Tu parles !? Le français dans tous ses états, Paris, Flammarion, 2000, p. 63-74.

15 Julia Kristeva, in La haine et le pardon: Pouvoirs et limites de la psychanlyse III, Paris, Fayard, 2005.
} 
rageuse et plus rude quand elle parle de la politesse et de l'évidence française, du goût français qu'elle définit ainsi : «un acte de politesse entre des gens qui partagent la même rhétorique dans une société stable », et qui opposent à l'étranger " un tissu social compact et un orgueil national imbattable ». Et de fustiger les autochtones de ce pays qui «s'identifient à leur parler poli et chéri » au point de déconsidérer ceux qui font un usage malencontreux de la langue française, ceux qui par leurs habitudes alimentaires ou vestimentaires dérogent «au goût universel, c'est à dire français ». Kristeva d'ailleurs ironise en retournant le cogito de Descartes : les français « des gens qui sont parce qu'ils pensent ». Et de distribuer qualités et défauts à ce peuple qui a fait la plus radicale des révolutions, ces français qui sont « les plus gais rouspéteurs du monde »: «Ecrire en français serait donc traduire la souffrance en goût de vivre $»^{16}$.

Cette distance critique rageuse ou pleine d'humour par rapport à la langue et la culture produite par «une société stable» se double du conflit intérieur, de la culpabilité, de la souffrance liée à l'abandon de la langue natale, langue du corps, « des pulsions innommables au voisinage du sens et de la biologie ». «Il y a du matricide dans l'abandon d'une langue natale », «Bulgarie ma souffrance », dit-elle en relevant qu'il y a « France » dans « souffrance ».

\section{«Il y a du matricide dans l'abandon d'une langue natale »}

Le bulgare est pour elle une «langue presque morte », d'abord métaphorisée en « eau lointaine », « source originelle » puis «vieux corps » cadavérisé, «crypte enfouie », « réservoir stagnant qui croupit et se délite » sur lequel elle a bâti une «nouvelle demeure », le français et une «sérénité ponctuée de mots français ». Entre les deux langues dont l'une s'est substituée à l'autre, règne l'antithèse donnée comme irréconciliable entre «les dorures noires des icônes orthodoxes », et «l'apparence lisse des mots français polis comme la pierre des bénitiers ». Et elle désigne ces moments où « une houle qui n'est pas de mots mais qui a sa musique bien à elle » lui impose « une syntaxe maladroite» et «ces métaphores abyssales» qui lui viennent de sa langue maternelle slave, la poussant à «déroger au goût français ». Il en résulte «un être hybride », produit d'une « greffe »; « le monstre qui s'en extrait » (l'image est très forte et désigne le surgissement contre-nature, dans un geste d'auto-engendrement violent

\footnotetext{
${ }^{16}$ Toutes les citations données proviennent de l'article « Écrire en français », op. cit.
} 
d'un alien, ) se voit voué à une parole «étrange, étrangère, ni d'ici, ni de là », à être « un monstre de carrefours ».

Ecrivaine migrante " enraciné(e) dans aucun langage et aucun sang »

On le voit toutes les images et métaphores traduisent un conflit violent, irréductible qui l'assigne douloureusement à la position d'étrangère, qui va finalement être revendiquée de façon militante, combative et prophétique : le «je » étrange surgi dans le texte «Ecrire en français» se résorbe dans le «nous» des «écrivains migrants », «enracinés dans aucun langage et aucun sang» «diplomates du dictionnaire », «négociateurs génétiques» «juifs errants de l'être», «humanité nomade » d'où viendrait peut-être le salut ou la réponse aux crispations identitaires qui ravagent la planète. En même temps que «l'autre langue de l'écriture » est désigné comme le lieu où se noue le «dialogue », elle aussi comme François Cheng, emploie ce mot, entre les deux langues.

\section{FRANÇOIS CHENG, OU LE DIALOGUE ENTRE L'ORIENT ET L'OCCIDENT}

François Cheng est universitaire, traducteur, poète, romancier ; il a été élu à l'Académie française en 2002 et raconte son parcours d'écrivain entre deux langues très éloignées dans «Le dialogue; Une passion pour la langue française ${ }^{17}$.C'est la révolution maoïste survenue au moment où il étudiait en France qui contraint François Cheng à rester dans le pays où il était venu poursuivre ses études. Il s'y situe d'abord dans une identité de «passeur» entre les deux cultures en traduisant en chinois les poètes français, puis en faisant connaître en France la peinture et la poésie chinoise. Première activité du passeur, la traduction. Mais c'est bien des années plus tard, quand il envisage de revenir à la poésie et qu'il choisit de l'écrire dans la langue française que s'illustre le dialogue entre les deux langues.

Un mariage d'amour et de raison avec la langue française

Lui aussi détaille les «vertus» de la langue française. Les mots «clarté », « rigueur», «précision» reviennent souvent sous sa plume: «langue de rigueur et de précision » pour ce poète chinois qui se déclare toujours poussé à «plus de rigueur dans la formulation, plus de finesse dans l'analyse ». Ces qualités de la langue s'épanouissent

\footnotetext{
${ }^{17}$ François Cheng, Le dialogue ; Une passion pour la langue française, Desclée de Brouwer,
} 2002. Toutes les citations données sont extraites de cet ouvrage. 
à merveille dans les textes théoriques. Pourtant, c'est en explicitant le dilemme ressenti au moment de choisir «l'outil» linguistique de sa poésie qu'il en vient à préciser la relation entre les deux langues.

Ce poète utilise de façon récurrente les termes de $d$ ' «osmose », de «symbiose», de «mariage», «mariage d'amour et de raison, pour illustrer leur dialogue intime : «j'ai embrassé la langue et épousé toute une tradition poétique » mettant cette alliance sous le signe de l'amour, de la «commune présence » ( en reprenant le titre d'un recueil de René Char), et de l'alliance exogamique. Sa poésie, nous dit-il, est issue de deux traditions poétiques « symbiosées » (c'est lui qui fabrique ce néologisme). La langue maternelle est qualifiée de «vieille nourrice fidèle »; si le français a été adopté comme outil de création, l'autre langue n'a pas pour autant été effacée, ni même mise en sourdine; elle continue d'agir en donnant des images à métamorphoser.

\section{L'artisan du dialogue entre l'orient et l'occident}

C'est sous l'angle d'une mise en perspective critique que s'inaugure sa tentative pour faire dialoguer «deux cultures qui creusent entre elles le plus grand écart qu'on puisse imaginer ». Au terme de cet itinéraire où il explique pourquoi il a choisi le français comme langue de création, il tente d'établir des passerelles, de voir comment les pensées orientales et occidentales peuvent se relier, s'interpénétrer et s'enrichir. Il prend appui sur la cosmologie chinoise et ses trois éléments, le ying, le yang et le vide médian pour mesurer les apports des deux civilisations et la manière dont elles peuvent s'enrichir l'une l'autre, voire se compléter au plan philosophique. Il remarque l'apport civilisationnel majeur de l'Occident qui a isolé le concept de sujet et a protégé son statut par des règles de droit. La Chine qui n'a pas assez détaché la personne humaine des liens qui l'environnent souffre, selon «ses intellectuels modernes » d'un "déficit du côté du deux » («le deux désignant le Sujet en face de l'Objet ou le Sujet en face d'un autre Sujet »); mais elle est en revanche du côté du «trois », par sa conceptualisation du vide médian qui entraîne le Ying et le Yang dans un processus d'interaction et de transformation mutuelle. Donc si la Chine a intérêt à se mettre à l'école de l'Occident en ce qui concerne la «pensée du deux », l'Occident, lui, peut s'inspirer de la Chine en ce qui concerne la « pensée du trois ». 
On voit donc ici que ces mises en perspective critique d'une culture par une autre jouent tantôt par rapport à la culture d'accueil (Julia Kristeva), ou tentent une synthèse philosophique des deux cultures comme le fait François Cheng. Alors que Kristeva se propulse au terme d'une naissance violente vers une hybridité nomade et guerrière, refusant la filiation du sang et du langage, François Cheng en arrive au terme d'un long travail de filiation sans heurt à se « ré-enraciner » dans l'« écart » entre les deux civilisations et à y tisser des points de passage.

Mais, chez ces deux auteurs, c'est à la création de la langue poétique ou littéraire qu'ouvre l'autre langue et à une expérience que tous les deux désignent comme « une expérience de l'être ». Elle permet à François Cheng de «re-nommer à neuf les choses » et «se ré-enraciner», «non seulement dans sa terre d'accueil, mais proprement dans l'être ». Et Kristeva évoque «l'alchimie de la nomination », où elle est «seule avec le français. Nommer l'être me fait être ». Finalement cette expérience de l'être en vient chez ces deux auteurs à transcender les conflits et les positions identitaires.

Cette expérience et celle d'un l'affranchissement et d'une nouvelle identité que Cheng formule ainsi « être à la fois en soi et autre que soi, ou alors en avant de soi dans une perspective multidimensionnelle ». Kristeva fait du destin des écrivains hybrides et migrants une réponse aux crispations identitaires qui ravagent certaines régions du monde et le rattache à celui d'une «humanité nomade qui ne veut plus se tenir tranquille sur sa chaise ».

\section{JANINE ALTOUNIAN : LA TRANSMISSION D'UN HERITAGE TRAUMATIQUE SOUS COUVERT D’UNE AUTRE LANGUE}

Janine Altounian n'eut pas à choisir sa langue. Le français lui fut imposé au lieu de l'arménien parlé autrefois « une langue hypothéquée par moi dans une sorte de nuit psychique ». Et c'est en 1981, sous l'effet de la prise d'otages au consulat de Turquie en septembre 81, acte terroriste rompant pour la première fois un silence d'un demi-siècle sur le génocide arménien, qu'elle se décida à publier dans Les temps modernes le journal de déportation de son père, puis à engager cette vaste fresque constituée par la 
trilogie $:^{18}$ «Ouvrez-moi seulement les chemins d'Arménie », «La survivance » et «L'intraduisible» où elle élabore les effets du génocide sur les descendants des rescapés survivants. Elle montre comment la langue et les institutions du pays d'accueil, appelées à une place de tiers, permettent aux survivants de meurtres collectifs de mettre en circulation un patrimoine anéanti et d'effectuer un travail de nomination, de deuil et de transmission. De là la nécessité pour l'écrivain-héritier d'en passer par la langue et les institutions de la culture d'accueil pour «tenter de symboliser l'événement nonadvenu à ses parents » qui les retint captifs de la terreur : « entre la terreur du meurtre et l'affranchissement hors de son emprise, il faut donc que se creuse, la plupart du temps dans les générations suivantes l'interstice d'une fonction symbolisante : la capacité à nommer cet événement, puis à dé-porter l'effondrement traumatique de l'histoire dans le champ de la représentation, dans le registre des mots $\gg{ }^{19}$.

Le salut par l'école de la république

Janine Altounian ne cesse de proclamer sa dette envers l'Ecole de la république, « ce tiers[...]garant de la vie et de la culture » « tiers incapable de comprendre mais capable d'accueillir» qui fut pour elle, comme pour d'autres survivants de meurtres collectifs, une «mère adoptive »; elle était, en effet, contrainte à « une double filiation entre des parents exterminables et d'autres qui, pour l'instant ne le seraient pas ». L'institution scolaire apportait à l'enfant prisonnier du silence et de l'emprise traumatique de ses ascendants «une langue, un imaginaire culturel différenciateurs et par là même, produisait à son insu du tiers ». Apprendre la langue de l'autre, prendre plaisir aux mots, à sa culture, à sa littérature lui offrait la possibilité de s'échapper « dans un monde fictif où, à côté du meurtre trop familier, il y aurait les plaisirs de la vie, plaisirs aux autres et à la poésie ». En même temps que s'éprouvait la capacité à passer de son monde à celui des autres, s'apprenaient les mots servant à témoigner. «Passer par l'autre et son langage pour faire advenir le sien »; telle fut l'opération de métissage salvatrice qui lui permit plus tard d'assurer la transmission de son héritage en « déportant le patrimoine traumatique dans la langue de l'autre».

\footnotetext{
${ }^{18}$ Janine Altounian, «Ouvrez-moi seulement les chemins d'Arménie ». Un génocide aux déserts de l'inconscient, Paris, Les Belles Lettres,coll. "Confluents psychanalytiques ", 1990. La survivance/Traduire le trauma collectif, Paris, Dunod, coll. "Inconscient et culture », 2000. L'intraduisible. Deuil, mémoire et transmission, Paris, Dunod, coll. "Psychismes », 2005.

${ }^{19}$ Cette citation ainsi que celles qui suivent sont extraites de L'intraduisible : Deuil, mémoire, transmission, op. cit.
} 


\section{La transmission différée de l'héritage sous couvert de la langue de l'autre}

L'opération de filiation est au cœur de la démarche de Janine Altounian: comment hériter de parents détruits psychiquement si ce n'est « en adoptant une posture d'engendrement des ascendants et de soi qui passe par la restitution d'une parole à ceux chez qui elle fut avortée ». «Ecrivain-témoignant», «héritiertranscripteur», «scribe des mutiques qu'il porte en lui », «l'héritier écrivain» « raconte leur histoire et ce-faisant, les événements du monde qui les ont rendu muets ».

Si la paradoxalité d'un tel travail d'énonciation est plusieurs fois soulignée par Janine Altounian, puisqu'elle passe par le détour d'une langue et une culture délibérément silencieuse ou passive dans ce qui provoqua le déracinement traumatique de cette communauté, ce détour n'en reste pas moins le seul salut possible, le seul mode d'inscription d'une catastrophe dont les héritiers se libèrent en s'en faisant les porteparole et en la déportant dans la langue de l'autre.

C'est dans les livres de Janine Altounian que se trouve formulée de la façon la plus forte la fonction de ce tiers salvateur pour la survie psychique que constitue la figure de l'étranger dont on adopte la langue, la culture et les institutions afin d'y inscrire une histoire menacée de s'engloutir et auquel on «confie » les traces de cet anéantissement afin de reconstituer le patrimoine et devenir ainsi « audible à soi-même et aux autres ».

\section{CONCLUSION}

C'est donc sur cette mise à jour, dans des circonstances extrêmes, de la fonction du tiers salvateur dans la figure de l'étranger que se conclura ma réflexion. Nos trois auteurs orchestrent dans sa diversité la dynamique, les douleurs et les stratégies du métissage ; les figures en sont le décentrement, le déplacement, la mise en perspective. Ils font de l'écart, du détour, du dépaysement les instruments de la conquête d'une liberté nouvelle. Aux intersections entre plusieurs mondes, ils tissent les liens entre l'Orient et l'Occident, le passé sous séquestre et le présent, l'horreur sans nom d'un génocide et ce qui peut en être transmis. Ils transforment une identité de carrefours en mode de connaissance de ce qui échappe à notre compréhension et à notre prise, franchissant les frontières entre les disciplines, bousculant les représentations, 
indifférents aux censures imposées traditionnellement par l'appartenance à un groupe ou à une communauté. En ce sens, ils me paraissent construire l'une des figures de la modernité au vingt et unième siècle, celle de ces subjectivités qui se construisent dans l'expérience de l'exil et du déplacement.

Ainsi, grâce à eux, notre réflexion a cherché à articuler les traumatismes historiques et individuels à la nécessité d'en passer par un tiers, représenté par la culture, la langue et les institutions du pays choisi pour les études ou élu comme terre d'adoption. Elle décèle sous les déplacements des étudiants - déplacements encouragés par les politiques actuelles qui insistent sur la «mobilité »- des forces subversives. Certains sont aux prises avec des catastrophes politiques, économiques, humaines qui ne peuvent se penser que dans l'écart différenciateur de pays disposant d'une société stable et d'institutions garantes de la culture et de l'altérité. D'autres se saisissent de l'opportunité de partir étudier ailleurs pour tenter d'élaborer soit dans leur travail de recherche, soit à l'occasion de rencontres dépaysantes, des interrogations inédites concernant leur pays, leur culture d'origine, leur désir. Dans tous les cas, ces questions sont déposées, hébergées, travaillées, soutenues dans l'université français et contribuent à son rayonnement.

Ainsi, les déplacements de ces avant-gardes me paraissent-ils offrir une chance pour les individus et les états qui les reçoivent de se sentir enrichis de la confrontation à l'étranger. Les cultures majoritaires de l'occident ont un rôle à jouer devant les éclatements et les remaniements incessants des frontières, les rééquilibrages économiques et politiques. Dans un monde mouvant et instable, où les zones de chaos se déplacent, ces cultures ont un devoir d'hospitalité dont le linguiste Benveniste nous rappelle que l'idée originelle émerge dans l'antiquité grecque et romaine comme le droit réciproque de trouver logement et protection les uns chez les autres.

Le pays, la langue et la culture de l'autre peuvent servir d'outils ou d'appuis pour mettre en perspective le pays d'origine, penser ce qui était inaccessible, oblitéré, escamoté, interroger ce qu'on ne savait pas connaître, formuler ce qu'on ne voyait pas dans les limites trop étroites d'un pays, d'une communauté ou d'une famille. Le détour par l'autre est fondateur pour revenir à soi ; chance est offerte de voir s'ouvrir des 
perspectives insoupçonnées, «des passages qu'on n'imaginait pas ${ }^{20}$ selon l'expression de Yosuke Morimoto.

\section{BIBLIOGRAPHIE}

Altounian J., «Ouvrez-moi seulement les chemins d'Arménie ». Un génocide aux déserts de l'inconscient, Paris, Les Belles Lettres,coll. «Confluents psychanalytiques », 1990.

Altounian J., La survivance/Traduire le trauma collectif, Paris, Dunod, coll. «Inconscient et culture », 2000.

Altounian J., L'intraduisible. Deuil, mémoire et transmission, Paris, Dunod, coll. «Psychismes », 2005.

Arendt H., La tradition cachée, Paris, Christian Bourgeois, «Bibliothèque 10/18 », 1987.

Beledian K. , Cinquante ans de littérature arménienne en France. Du même à l'autre, Paris, CNRS Éditions, 2001.

Gomez Mango E., «La langue et l'exil», Cahiers intersignes : Parcours d'exil, $\mathrm{n}^{\circ} 3$, automne 1991.

Hinsinger D. et Zaréa P., «Pourquoi faut-il aller si loin? », Communication faite au colloque «temps et déplacement », octobre 2004, Actes non publiés.

Jullien F., Conférence d'ouverture", in Étudier,chercher ailleurs : les étudiants étrangers dans l'université française, Paris, Cité-débats, Octobre 2004, p. 29-49.

Kristeva J., «Écrire en français » in Tu parles !? Le français dans tous ses états, Paris, Flammarion, 2000, p. 63-74.

Kristeva J., Étrangers à nous-mêmes, Folio essais, 1988.

Kristeva J., La haine et le pardon: Pouvoirs et limites de la psychanalyse III, Paris, Fayard, 2005.

Cheng F., Le dialogue; Une passion pour la langue française, Desclée de Brouwer, 2002

Morimoto Y., «De la servitude volontaire », in Étudier, chercher ailleurs : les étudiants étrangers dans l'université française, Paris, Cité-débats, Octobre 2004, p. 157-162.

\footnotetext{
${ }^{20}$ Yosuke Morimoto, « De la servitude volontaire », Etudier, chercher ailleurs, op. cit.
} 
Rouquet-Brutin K., «La transmission de la recherche d'une langue à l'autre », in Étudier, chercher ailleurs : les étudiants étrangers dans l'université française, Paris Cité-débats, Octobre 2004, p. 121-132.

Rouquet-Brutin K., «Dépaysement et mise en perspective de la recherche », Communication faite au colloque «Temps et déplacement», octobre 2004, Actes nonpubliés.

Rouquet-Brutin K., «Penser dans une autre langue », actes du colloque du Bureau D’Aide Psychologique Universitaire-Pascal, décembre 2006.

Rouquet-Brutin K., "la question des frontières ou l'appel à l'autre », in Mana, L'Harmattan, $\mathrm{n}^{\circ}$ 14-15, 2007.

Rouquet-Brutin: «Destins métisses et constructions identitaires: l'appel à l'autre langue, l'autre culture », Exils, migrations, création, Université Paris 12-Val de Marne, Ed. Indigo, 2008.

Rouquet-Brutin K., "Passer une frontière, trouver une langue », actes du colloque «Violence politique, traumatisme, processus d'élaboration et de création » à Louvainla-Neuve, mai 2009, à paraître.

RECEBIDO EM: 01 de novembro de 2012

APROVADO EM: 11 de dezembro de 2012 